\title{
ACTION RESEARCH THIRD EDITION (3RD. ED.) 2007 LOS ÁNGELES. SAGE PUBLICATIONS
}

*Asistente de Investigación; candidato a Doctor en Innovación Educativa en la Escuela Nacional de Educación Humanidades y Ciencias Sociales del Tecnológico de Monterrey. Publicaciones: https: itesm academia edu SandraGudiño

\section{Por: Sandra Gudiño Paredes*}

El enfoque de investigación-acción, al que hace referencia este libro, se presenta como una alternativa al enfoque cuantitativo, el cual parece ser una constante en la investigación educativa, asumiéndose como la forma ideal de generalizar resultados pero resulta poco eficiente cuando se pretende que las acciones se adecuen al contexto y situación de cada escuela porque su contexto es diferente y, por ende, las problemáticas que enfrentan cada día lo serán.

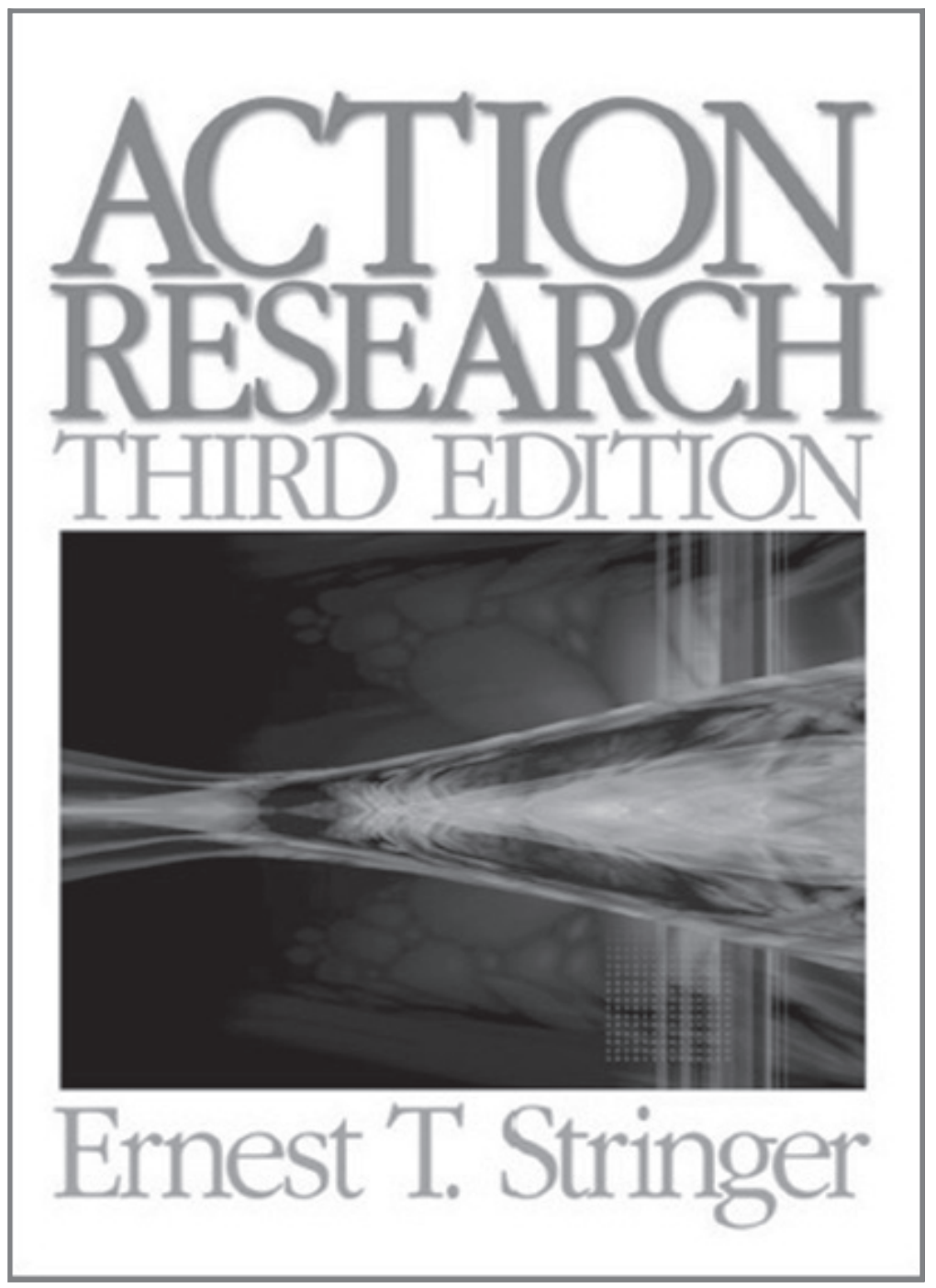

En el capítulo uno, el autor inicia con la definición de investigaciónacción, la cual busca sustentar con ejemplos en los capítulos posteriores. Para el autor, la investigación acción sería definida como un enfoque sistemático que le permite a las personas encontrar soluciones efectivas a los problemas a los que se enfrentan en el día a día. A diferencia de los enfoques experimentales y científicos tradicionales que buscan obtener explicaciones generalizadas que se apliquen a más bien todo contexto, la investigación acción se enfoca en situaciones específicas y en soluciones localizadas. Este tipo de enfoque también aportaría explicaciones prácticas que los distintos actores de la sociedad pueden utilizar en su práctica diaria para hacer su trabajo de forma más efectiva y significativa. 
En el segundo capítulo, el autor nos lleva de la mano hacia los fundamentos teóricos de la investigación acción y explica como es, que este enfoque de investigación tiene su fundamento en el paradigma de investigación cualitativa cuyo propósito es entender con la mayor claridad posible la pregunta, el problema o el tema que se está estudiando, como es natural parece contraponerse al paradigma positivista con sus mediciones y sistematizaciones rigurosas. Este enfoque parece tener una postura humilde al asumir un conocimiento limitado por parte del investigador para entender el problema que se pretende estudiar $y$ es por eso que remarca lo importante del conocimiento que tienen los que están directamente involucrados en el, incorporando sus propias perspectivas como parte integral del proceso de investigación.

En el capítulo tres, el autor expone el propósito principal de planear previamente las actividades, el cual consiste en establecer un clima positivo que contagie de energía y de entusiasmo a los participantes. Cualquier programa que fracase en atrapar el interés o compromiso de la gente a la que buscan ayudar se considerará inefectivo.

El capítulo cuatro se refiere a la etapa de conformar una imagen del proceso, la obtención de información que le permitirá a los investigadores aumentar su entendimiento del problema a través de la perspectiva y experiencias de los grupos de interés que están siendo afectados por el problema objeto de la investigación. El investigador debe entender a los participantes para poder pensar y trabajar en una solución viable en el que las personas pondrán a disposición su energía y su esfuerzo. En esta etapa los participantes están conscientes de lo valioso de su información.

En el capítulo cinco se exponen las primeras fases de la investigación, los participantes arrojan una gran cantidad de información para ser analizada. La tarea principal de la siguiente fase en este tipo de investigaciones es identificar aquellos aspectos de la información que permita al grupo de investigación entender la naturaleza de los eventos que se están investigando. Para el autor, análisis es el proceso de destilado de una gran cantidad de información con la finalidad de descubrir las características y elementos significativos que están ocultos en esos datos.

En el capítulo seis y después de haber presentado todos los pasos para realizar de la mejor manera una investigación participativa, el autor habla de como los participantes inician un trabajo conjunto de planeación e implementación 
Sandra Gudiño Paredes

de planes de acción que representen soluciones a los problemas tratados, lo cual constituye la parte medular de este enfoque.

En el capítulo siete de este libro, el autor concluye remarcando la importancia de asegurarse de que los cambios generados por este enfoque se constituyan en procesos que estén integrados sistemáticamente en la vida de la entidad, organización, departamento o institución en la que se realizó la investigación. Afirma que la cantidad de personas involucradas en el proceso puede ser proporcional a la duración de los cambios logrados por medio de este enfoque, es decir que mientras haya mas personas involucradas de la organización el cambio será más consistente y duradero.

En el capítulo ocho se define la elaboración de reportes formales requeridos por los grupos de interés que están dentro de los contextos institucionales u organizacionales sobre el proceso de investigación y los análisis detallados de sus resultados. El autor nos presenta en este capítulo un marco para la construcción de informes formales que conllevan el rigor y eficacia del enfoque de investigación-acción.

El propósito de este tipo de reportes formales, tesis y disertaciones es el de comunicar los resultados de la investigación a estos grupos de interés, generalmente integrados por personal académico o burocrático y, por tanto, deben ser presentados de forma aceptable para estos contextos.

En el capítulo nueve se remarca la importancia de la teoría en este enfoque de investigación. Uno de los puntos medulares de la investigación-acción es la aceptación de las diversas perspectivas que intentan explicar el cómo y por qué se producen los eventos y que les permitan trabajar hacia una solución del problema investigado. Asume que no es posible adentrarse en un proceso de investigación fuera de la teoría. Stringer afirma que los procedimientos basados en la comunidad y en la participación activa de las personas en la formulación y el control de actividades y eventos de investigación son difíciles de alcanzar y difíciles de mantener, cuando que se puede lograr, sin embargo, proporcionan un poderoso medio para alcanzar cualquier conjunto de objetivos sociales o profesionales. 

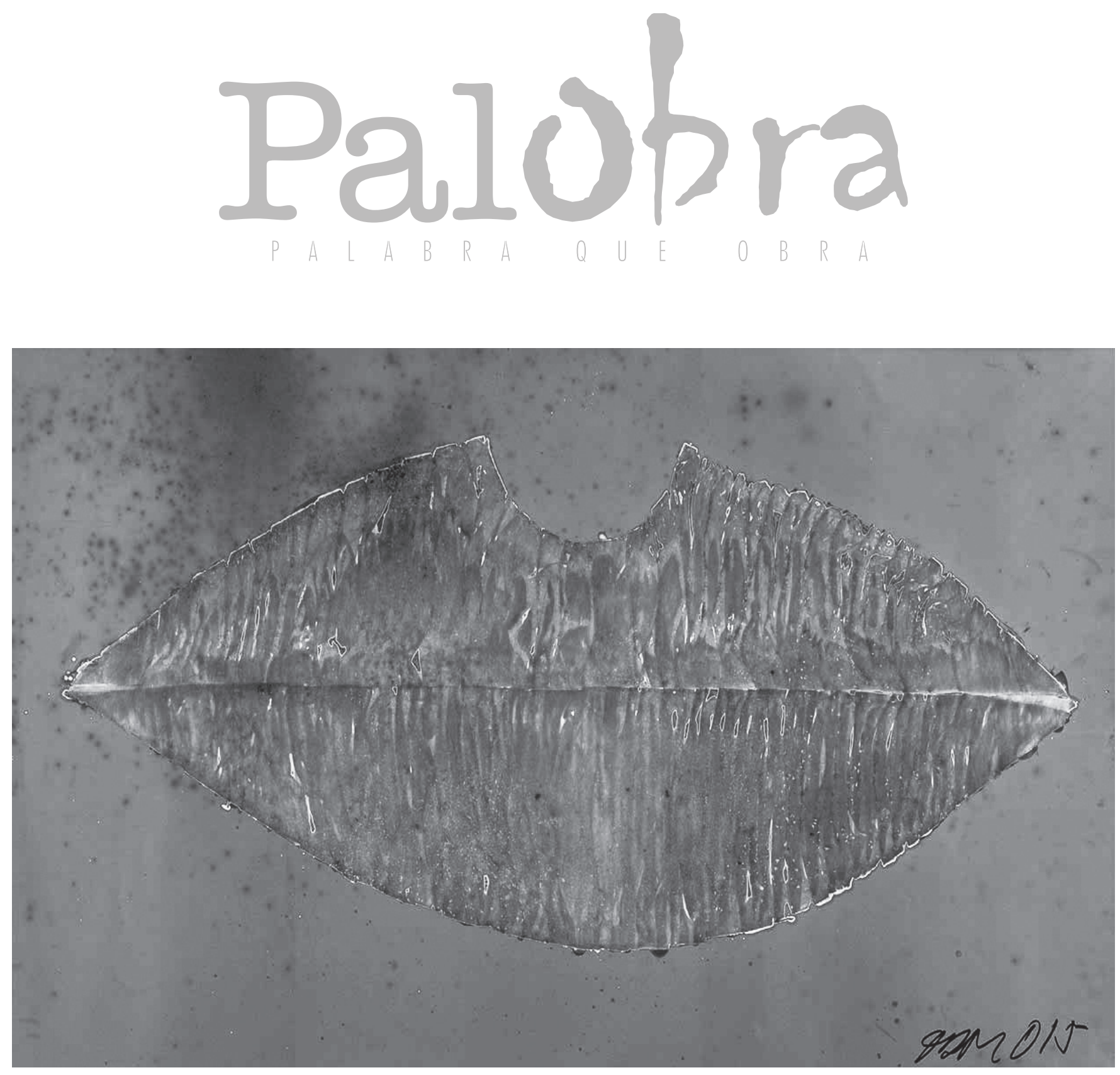

Labios. 2015.

Impresión fotográfica sobre papel emulsionado. 